\title{
Evaluation of carbon dioxide storage potential for the Bohai Basin, north-east China
}

Ceri Vincent $^{\mathrm{a}^{*}}$, Niels E. Poulsen ${ }^{\mathrm{b}}$, Zeng Rongshu ${ }^{\mathrm{c}}$ Dai Shifeng $^{\mathrm{d}}$, Li Mingyuan ${ }^{\mathrm{e}}$ and Ding Guosheng ${ }^{\mathrm{f}}$

${ }^{a}$ Kingsley Dunham Centre, British Geological Survey, Keyworth, Nottingham, NG12 5GG, UK

${ }^{b}$ Geological Survey of Denmark and Greenland, Department of Geophysics, Oster Volgade 10, DK1350 Copenhagen K, Denmark

${ }^{c}$ Institute of Geology and Geophysics, Chinese Academy of Sciences, Beijing 100029, China

${ }^{d}$ State Key Laboratory of Coal Resources and Safe Mining, China University of Mining and Technology (Beijing), Beijing 100083, China

${ }^{e}$ Enhanced Oil recovery research Centre, China University of Petroleum Beijing, 18 Fuxue Road, Changping, Beijing 102249, China

${ }^{f}$ Research Institute of Petroleum Exploration and Development, PetroChina Company, Ltd, Langfang, PO Box 44, Langfang, Hebei Province, 065007, China

* Corresponding author Ceri Vincent, cvi@bgs.ac.uk telephone 00441159363318 Fax 0044115 9363200

\begin{abstract}
The storage potential of selected sites within the Bohai Basin was assessed for the $\mathrm{COACH}$ project. The Gangdong Oilfield is considered to have a small potential storage capacity $(23 \mathrm{Mt}$ ) and to be possibly suitable for an EOR or small scale storage pilot rather than large-scale storage. The Shengli oilfield province is considered to have a great potential storage capacity ( $472 \mathrm{Mt}$ in eight selected fields), however, these fields, like those of the Gangdong oilfield province, are compartmentalised by faulting and stratigraphy and likely to be quite challenging for injection. Unmineable coalseams in the Kailuan mining area were also considered for storage, the estimated capacity is $504 \mathrm{Gt}$ adsorbed onto the coal and $38100 \mathrm{Mt}$ void storage capacity. However, the coals have low porosity and permeability, so they would be expected to have poor injectivity. This is also an active mining area and so any storage site would have to be chosen carefully to avoid affecting future energy resources. The Huimin sub-basin within the Jiyang Depression was identified for consideration as an aquifer storage site; the Guantao Formation has good porosity and permeability in this region, and the regional-level storage capacity of these areas was estimated to be 0.7 Gt. The aquifers in the Huimin-sub basin appear promising for storage, however, less data are available than for the oilfields and the sealing formations are not directly proven to trap buoyant fluids, though in adjacent oilfield in the Shengli oilfield province, the Minghuazhen Formation forms a regional seal for the Guantao Formation.
\end{abstract}

Keywords: $\mathrm{CO}_{2}$ storage; Bohai Basin; $\mathrm{COACH}$; Dagang; Shengli; Kailuan; Jiyang

\section{Introduction}

The Cooperation Action within Carbon Capture and Storage China-EU project $(\mathrm{COACH})$ is a three-year EC Framework 6 co-funded collaborative project. Storage potential of selected sites in the Bohai Basin (north-east China) has been evaluated by Chinese scientists using published data with support from EU partners. Most industrial development and therefore the majority of large sources of carbon dioxide $\left(\mathrm{CO}_{2}\right)$, lie along the eastern coastline and consequently storage sites are being sought in this area. The storage sites considered were the Dagang oilfield province (Tianjin Municipality), Shengli oilfield province (Shandong Province), Kailuan mining area (Hebei Province) and deep saline aquifers in the Jiyang Depression (Shandong province) (Figure 1). 


\section{Methodology}

A regional level assessment of selected potential storage sites for $\mathrm{CO}_{2}$ in the Bohai Basin was carried out for the $\mathrm{COACH}$ project. The storage capacity was estimated in each case using a simplified version of the Carbon Sequestration Leadership Forum (CSLF) methodology (Bachu et al., 2007). The storage reservoir properties, sealing formation properties, reservoir injectivity and other relevant parameters were also considered. For all sites considered, publicly available data were used. PetroChina also provided data for the Dagang oilfield province and the China University of Mining and Technology carried out experiments on coal samples to improve the accuracy of the storage assessment.

The storage capacity of the oilfields was estimated using the following equation:

$\mathrm{M}_{\mathrm{CO} 2 \mathrm{e}}=\left(\mathrm{URR}_{\mathrm{stp}} \cdot \mathrm{B}_{\mathrm{o}}\right) \cdot \rho_{\mathrm{CO} 2} \cdot \mathrm{S}_{\mathrm{coeff}}$

Where

$\mathrm{M}_{\mathrm{CO} 2 \mathrm{e}}=$ estimated effective storage capacity (Mt)

URRstp = Ultimately Recoverable Reserves (at standard temperature and pressure)

(Mt converted to $\mathrm{m}^{3}$ using API of oil)

$\mathrm{B}_{\mathrm{o}}=$ Formation volume factor (Assumed to be 1.1 due to lack of data)

$\rho_{\mathrm{CO} 2}=$ Density of $\mathrm{CO}_{2}$ in the reservoir $\left(650 \mathrm{~kg} / \mathrm{m}^{3}\right.$ Poulsen et al., 2009)

$\mathrm{S}_{\text {coeff }}=$ storage coefficient to discount for water invasion etc $(0.3)$

The storage capacity of the Shengli oilfield province was also estimated by the China University of Beijing (CUPB) using a methodology based on Tanaka et al, (1995) which assumes that $\mathrm{CO}_{2}$ will displace pore fluids and rapidly dissolve into the pore fluids:

$\mathrm{M}_{\mathrm{CO} 2}=\mathrm{M}_{1}+\mathrm{M}_{2}+\mathrm{M}_{3}$

Where

$\mathrm{M}_{\mathrm{CO} 2}=$ estimated storage capacity of $\mathrm{CO}_{2}$ summed for all reservoirs in the oilfield

$\left(\mathrm{m}^{3}\right)$. This was converted to tonnes assuming $\mathrm{CO}_{2}$ density of $650 \mathrm{~kg} / \mathrm{m}^{3}$.

$\mathrm{M}_{1}$ is the storage capacity of $\mathrm{CO}_{2}$ dissolved in oil and water in the oil bearing

reservoir

$\mathrm{M}_{2}=$ storage capacity of $\mathrm{CO}_{2}$ dissolved in the water-bearing formation in contact with the oilfield

$\mathrm{M}_{3}=$ storage capacity of $\mathrm{CO}_{2}$ replacing oil in the oil bearing reservoir during $\mathrm{CO}_{2}$

flooding

Substituting these into equation [2] gives

$\mathrm{M}_{\mathrm{CO} 2}=\mathrm{E}_{\mathrm{f}} \times \mathrm{A}_{\mathrm{o}} \times \mathrm{h}_{\mathrm{o}} \times \varphi \times\left[\mathrm{S}_{\mathrm{o}} \times \mathrm{R}_{\mathrm{o}(\mathrm{CO} 2)}+\left(1-\mathrm{S}_{\mathrm{o}}\right) \times \mathrm{R}_{\mathrm{w}(\mathrm{CO} 2)}\right]+\mathrm{h}_{\mathrm{o}} \times \mathrm{A}_{\mathrm{o}} \times \varphi \times \mathrm{S}_{\mathrm{w}}+\left(\mathrm{M}_{\mathrm{p}} \times 4 \% / \rho_{\mathrm{f}}\right)[3]$

Where

$E_{f}=$ overall sweep efficiency (fraction), $E_{f}=5 \%-25 \%$

$\mathrm{A}_{\mathrm{o}}=$ area of oil-bearing reservoir $\left(\mathrm{m}^{2}\right)$

$\mathrm{h}_{\mathrm{o}}=$ thickness of reservoir $(\mathrm{m})$

$\varphi=$ porosity of reservoir (fraction)

$\mathrm{S}_{\mathrm{o}}=$ oil saturation in reservoir (fraction) 
$\mathrm{R}_{\mathrm{O}(\mathrm{CO} 2)}=\mathrm{CO}_{2}$ solubility in oil (fraction)

$\mathrm{R}_{\mathrm{w}(\mathrm{CO} 2)}=\mathrm{CO}_{2}$ solubility in water(fraction)

$\mathrm{S}_{\mathrm{w}}=\mathrm{CO}_{2}$ solubility in formation water (fraction)

$\mathrm{M}_{\mathrm{p}}=$ residual oil in reservoir $\left(10^{4} \mathrm{t}\right)$ (from published data for 2000$)$

$\rho_{\mathrm{f}}=$ oil density in formation $\left(\mathrm{kg} / \mathrm{m}^{3}\right)$

Sweep efficiency, $\mathrm{E}_{\mathrm{f}}$ varies between $5 \%$ and $25 \%$ based on typical reservoir properties. In the Shengli oilfield province, it was assumed to be $12 \%$. When $T=45^{\circ} \mathrm{C}$, $P=12.7 \mathrm{MPa}, R_{\mathrm{w}(\mathrm{CO} 2)}=5 \%$ (mass) and $R_{\mathrm{o}(\mathrm{CO} 2)}=15 \%$ (weight percentage) and the formation water had salinity over $10000 \mathrm{mg} / \mathrm{L}, R_{\mathrm{w}(\mathrm{CO} 2)}$ was assumed to be $4.2 \%$ $\left(0.07 \mathrm{~m}^{3} / \mathrm{m}^{3}\right)$, otherwise a value of $5 \%\left(0.083 \mathrm{~m}^{3} / \mathrm{m}^{3}\right)$ was used for $R_{\mathrm{w}(\mathrm{CO} 2)} . R_{\mathrm{O}(\mathrm{CO} 2)}$ is $\left(0.160 \mathrm{~m}^{3} / \mathrm{m}^{3}\right)$. It was assumed that $\mathrm{CO}_{2}$ solubility in the formation water $\left(S_{\mathrm{w}}\right)$ was the

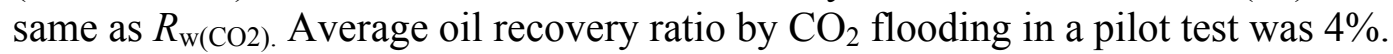

Using a CSLF-based methodology (Bachu et al 2007), the storage potential of unmineable coal seams was calculated using the following equation:

$\mathrm{M}_{\mathrm{CO} 2 \mathrm{e}}=\rho_{\mathrm{CO} 2 \mathrm{~s}} \times \mathrm{A}_{\mathrm{c}} \times \mathrm{h}_{\mathrm{c}} \times \mathrm{n}_{\mathrm{c}} \times\left[\mathrm{V}_{\mathrm{L}} \times \mathrm{P} /\left(\mathrm{P}+\mathrm{P}_{\mathrm{L}}\right)\right] \times\left(1-\mathrm{f}_{\mathrm{a}}-\mathrm{f}_{\mathrm{m}}\right) \times \mathrm{ER} \times \mathrm{C} \times \mathrm{R}_{\mathrm{f}}$

Where $\mathrm{M}_{\mathrm{CO} 2 \mathrm{e}}=$ estimated effective $\mathrm{CO}_{2}$ storage capacity $(\mathrm{kg})$

$\rho_{\mathrm{CO} 2 \mathrm{~s}}=$ density of $\mathrm{CO}_{2}$ at the standard temperature and pressure $\left(1.873 \mathrm{~kg} / \mathrm{m}^{3}\right)$

$\mathrm{A}_{\mathrm{c}}=$ area of the coal zone

$\mathrm{h}_{\mathrm{c}}=$ effective thickness of the coal zone

$\mathrm{n}_{\mathrm{c}}=$ the bulk coal density (generally $\mathrm{n}_{\mathrm{c}} \approx 1.4 \mathrm{t} / \mathrm{m}^{3}$ )

$f_{a}=$ ash weight fraction of the coal

$\mathrm{f}_{\mathrm{m}}=$ moisture weight fraction of the coal

$\mathrm{V}_{\mathrm{L}}=$ Langmuir volume constant (SCF/tonne)

$\mathrm{P}_{\mathrm{L}}=$ Langmuir Pressure constant (psia)

$\mathrm{ER}=$ ratio of $\mathrm{CO}_{2}$ adsorbed to methane desorbed

$\mathrm{R}_{\mathrm{f}}=$ recovery factor (fraction of gas that can be produced from the coal seam)

$\mathrm{C}=$ completion factor (estimate of the cumulative coal thickness that will contribute to gas production or storage)

Storage capacity was estimated using a simplified version of the CSLF method for aquifers (Bachu et al., 2007):

$\mathrm{M}_{\mathrm{CO} 2 \mathrm{e}}=\mathrm{A}_{\mathrm{a}} \mathrm{h}_{\mathrm{a}} \varphi \rho_{\mathrm{CO} 2 \mathrm{r}} \mathrm{S}_{\text {coeff }}$

Where

$\mathrm{M}_{\mathrm{CO} 2 \mathrm{e}}=$ effective estimated storage capacity (tonnes)

$\mathrm{A}_{\mathrm{a}}=$ area of the aquifer $\left(\mathrm{m}^{2}\right)$

$\mathrm{h}_{\mathrm{a}}=$ height of the aquifer $(\mathrm{m})$ multiplied by the net:gross ratio (the ratio of thickness

of sandstone in the aquifer to overall aquifer height)

$\varphi=$ average porosity of the aquifer $(\%)$

$\rho_{\mathrm{CO} 2 \mathrm{r}}=$ density of $\mathrm{CO}_{2}$ at reservoir conditions $\left(650 \mathrm{~kg} / \mathrm{m}^{3}\right)$

$\mathrm{S}_{\text {coeff }}=$ storage coefficient (Set as $2 \%$ based for this regional estimate based on results from the GeoCapacity Project, Vangkilde-Pederson et al., 2008, Bachu 2008)

\section{Dagang oilfield province}


The Dagang oilfield province lies in the Huanghua Depression of the Bohai Basin. Exploration began in 1955; numerous wells have been drilled and water flooding is used to maintain reservoir pressure during production. Storage potential for the Dagang oilfield province was assessed using publicly available information and data provided by the Research Institute of Petroleum Exploration and Development (PetroChina) (RIPED). The main oil and gas reservoir formations are the Neogene Dongying, Guantao and Minghuazhen formations (Figure 2). Initially, the storage capacity for seven selected reservoirs was estimated using the simplified version of the CSLF methodology described above (equation 1). Applying this to the seven selected reservoirs in the Gangzhong, Shenshvi, Gangdong, Gangxi and Wangguantun fields, gives an estimated storage capacity of $22 \mathrm{MtCO}_{2}$. This estimated storage capacity used data on the oilfield provided by RIPED, with the exception of the $\mathrm{B}_{\mathrm{o}}$ which was obtained from published data. The uncertainty in the field data is low, however, as the storage coefficient is based on published data from reservoir models from geologically simpler oilfields, the field would need to be studied in more detail and reservoir simulations would be required to improve confidence in this estimate.

The Gangdong Oilfield was believed to have the largest capacity and so was selected by RIPED for more detailed study. The oilfield lies in the Beidagang Structural Belt, a region characterised by multi-phase intensive faulting, variable lithology and lithofacies, overlapping formations and many unconformity surfaces. The north margin of the Gangdong Oilfield is marked by the Gangdong Fault which was active during the Tertiary Period. The hydrocarbon bearing interval reaches a thickness of up to $1000 \mathrm{~m}$, and oil is buried at depths of $1000 \mathrm{~m}$ to $2000 \mathrm{~m}$. The main hydrocarbonbearing formations in this field are the Guantao and Minghuazhen formations. Each of these formations comprises numerous thin and often isolated sand bodies and lenses of $2-10 \mathrm{~m}$ thickness, surrounded by mudstone. Over 600 wells have been drilled to exploit this resource. The reservoirs of the Guantao Formation are usually oil-bearing with lesser amounts of associated gas and the reservoirs of the Minghuazhen Formation are mainly gas-bearing. Ultimately recoverable reserves were estimated at almost 90 Mt oil.

The Guantao Formation comprises cream sandstone - siltstone and grey mudstone, believed to have been deposited in a braided river system. Sandstones of the Guantao Formation have average porosities and permeabilities of $31 \%$ and $975 \mathrm{mD}$ respectively. These reservoirs are sealed by mudstones of the lower Minghuazhen Formation, which form a regional seal or mudstones within the Guantao Formation. The Minghuazhen Formation comprises red - green continental clastic sediments deposited in oxidizing conditions. The sedimentary sequence clearly shows a finingupward point bar sequence, from conglomerate to mudstone, believed to have been deposited in a meandering river system. These reservoirs are sealed by younger Minghuazhen Formation claystones.

Using the simplified methodology described above storage capacity of the Gangdong Oilfield was estimated to be $8 \mathrm{MtCO}_{2}$. Despite good porosities and permeabilities within the sandstone bodies, injectivity of these sandstones is expected to be poor as the fields comprise many small reservoirs, which are compartmentalised by faulting and stratigraphy. Overall, the Gangdong field is not suitable for large-scale storage of $\mathrm{CO}_{2}$, however, a small pilot for $\mathrm{CO}_{2}$ - EOR could be considered, though careful consideration into potential leakage pathways through boreholes and faults would be needed. Wells in which resistant cements have not been used may be vulnerable to 
corrosion of cement by carbonic acid formed when $\mathrm{CO}_{2}$ mixes with water - this is a consideration for any storage site. As there are numerous wells drilled in the Dagang Oilfield province, potential corrosion of wellbores needs to be given serious consideration as wells in operation and completed wells have not been constructed with exposure to $\mathrm{CO}_{2}$ in mind.

\section{Shengli oilfield province}

The Shengli oilfield province lies in the Jiyang Depression in the northern Shandong Province near the mouth of the Yellow River. Published data for 2000 indicates the Shengli Oilfield includes about 65 oilfields and two gasfields covering an aerial extent of about $2117 \mathrm{~km}^{2}$. The majority of oil reserves $(90 \%)$ lie at depths between 950 and $3200 \mathrm{~m}$. The oilfields selected for storage potential assessment were the Shengtuo, Donxin, Xianhezhuang, Caoqiao, Bamianhe, Binnan, Shanjiasi and Gudao. The main reservoir formations in these oilfields lie within sandstone bodies within the Shahejie and Guantao formations. The Shahejie Formation comprises dark grey mudstone and cream sandstone interbedded with yellow-brown siltstone. The Guantao Formation comprises grey pebbly sandstone intercalated with grey - green mudstones. Both these formations are fluvial in origin. The Guantao Formation reservoirs are sealed by intra-formation mudstones or the regional seal of the Minghuazhen Formation.

Reservoirs in the Shahejie Formation are sealed by mudstones within the formation or the overlying Dongying Formation. The sandstones of the Guantao Formation in the Gudao oilfield are also of similar reservoir quality with average porosity $33 \%$ (range 28-35\%) and permeability average $3118 \mathrm{mD}$ (range 510-3,100 mD) (C\&C reservoirs 1998).

The properties of crude oil in the Shengli oilfield province are highly variable; the relative densities of crude oils range from 0.7604 to $1.0866 \mathrm{~g} / \mathrm{cm}^{3}$, viscosity of the oils varies from $4.44-84576 \mathrm{mPa}$.s. The sulphur content of the crude oils ranges from 0 to $13.9 \%$ and the pour point of the oils is -34 to $55^{\circ} \mathrm{C}$. The proportion of crude oil with higher relative density and higher viscosity increases gradually through the strata from older to younger rocks. During enhanced oil recovery, in particular with $\mathrm{CO}_{2}$ EOR, deposition of asphaltene and paraffins can be a problem, so oils with low quantities of these impurities and a high pour point (ability to hold asphaltene and paraffin in solution to avoid scaling issues) are preferred (Donaldson et al., 1989). About $55 \%$ of the formation water in the Shengli Oilfield Province is $\mathrm{CaCl}_{2}$ and $\mathrm{Cl}$ $\mathrm{Na}$ rich. Salinity of the formation water ranges from 20000 to $60000 \mathrm{mg} / \mathrm{L}$.

The same simplified CSLF-based methodology described for the Dagang field was applied to evaluate storage potential of the Shengli oilfields. The storage potential of selected fields in the Shengli oilfield province complex was estimated to be $472 \mathrm{Mt}$ using the CSLF-based methodology (equation 1), the largest capacity being in the Shengtuo Oilfield at $186 \mathrm{Mt}$. The China University of Petroleum (Beijing) used an alternative method of calculating storage capacity, based on Tanaka et al., 1995, which estimated the storage capacity of the Shengli oilfields to be $463 \mathrm{Mt}$ using equation 3. The Shengtuo Oilfield again had the largest estimated storage capacity of $108 \mathrm{Mt}$ (assuming $\mathrm{CO}_{2}$ density $650 \mathrm{~kg} / \mathrm{m}^{3}$ ). 
Both these storage estimates are based on published data from 2000 - the most recently published oilfield data (remaining reserves, reservoir thickness and area, oil properties). As a result, there is quite high uncertainty in these estimates. This emphasises the importance of cooperation with oil companies and other stakeholders in China; as SINOPEC were not a partner of the COACH project, this part of the assessment was purely dependent on published data.

Enhanced oil recovery and security of energy supply are key considerations for China. The potential for enhanced oil recovery was also estimated by CUPB. The Shengli oilfield province storage potential was also evaluated using a method applied by the China University of Petroleum Beijing (CUPB) based on displacement of pore water and dissolution of $\mathrm{CO}_{2}$ into porewater and oil; $\mathrm{CO}_{2}$ can assist recovery by dissolving into the oil reducing viscosity or by pushing oil towards the production boreholes. The additional oil which could be recovered by EOR was calculated to be approximately $23-112$ Mt using yield rates of $2-10 \%$.

The Shengli oilfield province has larger estimated capacities than the Dagang oilfield province, the reservoirs are however also compartmentalised by faulting and stratigraphy which is expected to cause poor injectivity for $\mathrm{CO}_{2}$. There are also numerous boreholes which could offer potential route for $\mathrm{CO}_{2}$ to the surface if not properly completed. The field could be considered for small scale storage, however, a more detailed investigation would be required to improve confidence, this would require access to detailed data such as seismic which is not available in the public domain.

\section{Kailuan mining area}

Kailuan mining area lies in the north Bohai Basin and includes the Kaiping and Jiyu coalfields. The Kailuan Mining Area lies within a high seismicity risk region, which needs to be taken into consideration in terms of security of storage; investigation would be needed to determine if movement along faults potentially compromise the seal and permit any free $\mathrm{CO}_{2}$ to escape into the overlying strata and to the surface. The mining area contains an estimated $3750 \mathrm{Mt}$ coal reserves of Carboniferous and Permian age which lie within the Shihezi, Shanxi, Taiyuan and Benxi formations (Figure 3). The thickness of Carboniferous-Permian strata is $490 \mathrm{~m}$ to $530 \mathrm{~m}$, which includes 15 to 20 coal beds with cumulative thickness of $20 \mathrm{~m}$ to $28 \mathrm{~m}$. The area in which coalbed methane (CBM) is exploited covers $900 \mathrm{~km}^{2}$ and uses coalseams at depths of up to $2000 \mathrm{~m}$ in the Kailuan mining area. Total estimated CBM reserves are over 70 billion $\mathrm{m}^{3}$. Pore fluid flow in aquifers between the coalseams is $0.1-0.7$ L/s.m.

The coals are low rank with a moderate degree of coal metamorphism. The coal is mainly gas coal, fat coal and coking coal. Porosity of the coal seams in the Shanxi Formation is $0.5 \%$, and permeability is $3.5 \mathrm{mD}$. The Langmuir volume is $32.76 \mathrm{~m}^{3} / \mathrm{t}$ and the Langmuir pressure is 3.0 MPa. The roof and soleplate of the coal bed is compact sandstone and mud stone, which is an effective trap for CBM.

Carbon dioxide injected into coal is preferentially adsorbed on to the coal, displacing coalbed methane, and potentially providing an additional energy resource (enhanced coalbed methane or ECBM recovery). As Kailuan is an active coal-mine, ECBM could only be applied at sites where there was no risk of contamination of resources 
or leakage through contact with future, active or abandoned coal mines. Site screening determined that uneconomic seams are present at suitable depth for $\mathrm{CO}_{2}$ storage. Permeability is a determining factor in the viability of a $\mathrm{CO}_{2}$ storage site, and currently it is considered that coal permeability has to be greater than $1 \mathrm{mD}$ for successful $\mathrm{CO}_{2}$ injection and/or coalbed methane (CBM) production. Coal swells as $\mathrm{CO}_{2}$ is adsorbed, which further reduces permeability and injectivity (Benson et al., 2005). Coal swelling generally increases with increasing gas affinity to coal (e.g., $\mathrm{CO}_{2}$ versus methane) and may reduce permeability by two orders of magnitude or more (Shi and Durucan 2005, Cui et al., 2007).

In the Kaiping Coalfield, in the east of the Kailuan mining area, the ash content of the coals varies from less than $15 \%$ to more than $25 \%$ and most the seams are low sulphur coals. Porosity and permeability were generally low in the Kaiping coalfield with the most favourable properties found in samples from the Tangshan coalmine for the Early Permian Taiyuan Formation coal with porosity $3.7 \%$ and permeability $3.6 \mathrm{mD}$. Coals in the Jiyu Coalfield in the west of the Kailuan mining area have been affected by igneous intrusion and volcanic activity and the ash content is generally high.

Experiments were carried out by the China University of Mining and Technology on coals from Majiagou Mine (MK-9) and Linnancang Mine (LNC-11), taken from the Kaiping and Jiyu coalfields respectively. Comparison of three different theoretical methods for estimating adsorption demonstrated the importance of experimental results for calculating absorption properties and thereby for estimating $\mathrm{CO}_{2}$ storage capacity. Samples were subjected to isothermal adsorption experiments and proximate analysis (moisture, ash and volatile matter, sulphur content and vitrinite reflectance were determined). The maceral compositions were determined to be favourable for $\mathrm{CO}_{2}$ adsorption. Overall the adsorption capacity of the medium rank MK-9 sample was higher than that of the low rank LNC-11 sample.

Using the simplified CSLF methodology (equation 4), the capacity of the Kailuan mining area was estimated to be $504 \mathrm{Gt}$. In addition to the amount of $\mathrm{CO}_{2}$ that could be adsorbed onto the coal, the amount of $\mathrm{CO}_{2}$ that could potentially be stored in exhausted coalmines (the void storage capacity) was estimated to be $38100 \mathrm{Mt}$ for the Kailuan mining area. Although the storage capacities are estimated to be large, the coals have low permeability (up to $3.6 \mathrm{mD}$ ) and porosity (average $3.5 \%$ ), so injectivity is expected to be low and as this is an active mining area, any storage site would have to be chosen with care to avoid affecting future energy resources and mining activities. The uncertainty in the storage capacity estimates is high as these adsorbtion tests were carried out on powdered coal samples, obtaining the maximum theoretical adsorption capacity. In the underground coal seams, storage capacity will actually be strongly limited by the generally low permeability of these coals.

The coals are well sealed by overlying mudstones, which could potentially trap $\mathrm{CO}_{2}$. However, these potential caprocks are penetrated by faults, CBM boreholes and coal mines which could provide potential leakage pathways to the surface.

\section{Jiyang Depression}

The oil-bearing Jiyang Depression lies in the central Bohai Basin. It covers an area of around $20000 \mathrm{~km}^{2}$ and is subdivided into six sag basins. The Institute of Geology and Geophysics (Chinese Academy of Sciences) evaluated the potential for storage in this 
region. Through initial site screening, the Neogene aquifers and in particular the Guantao Formation were determined to show the most promise; they lie at suitable depth (greater than $1000 \mathrm{~m}$ ), have a broad areal distribution and good connectivity between fault blocks. After further site screening, the Huimin sub-basin in the east of the Jiyang Depression was selected for further study as it has limited oil exploitation to conflict with potential storage activities.

The Guantao Group comprises partially cemented and fractured gravel rocks overlain by thick mudstones of the Lower Minghuazhen Formation. The sediments of the Guantao Formation are widely distributed across the Jiyang Depression, with great thickness, good connectivity and saline formation water. The lower part of the Minghuazhen Formation comprises mudstones and forms a potential regional seal, while the upper parts of the formation comprises a set of sandstones and mudstones of fluvial facies containing the fresh ground water resource in the area. The Guantao Formation comprises a 300 - 900 m thick unit of conglomeratic sandstone and sandstone with mudstone intercalations. The depth of the formation is more than 1000 $\mathrm{m}$ and it is overlain by $800-900 \mathrm{~m}$ of the Minghuazhen Formation comprising mudstone with siltstone intercalation.

Borehole information indicates groundwater flow from the margins towards the centre of the depression with stable pore-water chemistry. The hydrochemistry of the aquifers mainly consists of $\mathrm{CaCl}_{2}$ (calcium carbonate) rich water. Sodium bicarbonate $\left(\mathrm{NaHCO}_{3}\right)$ rich water only occurs on the north and south margins of the Jiyang Depression. The average total dissolved solid (TDS) is $10-20 \mathrm{~g} / \mathrm{L}$. The ratio of $\mathrm{Na} / \mathrm{Cl}$ in most areas is less than $1 \mathrm{~g} / \mathrm{L}$. The hydrochemical characteristics indicate that the groundwater flows from the margin to the centre of the depression. In general, the solubility of $\mathrm{CO}_{2}$ in formation water decreases with the increasing salinity of the formation water due to increased water viscosity and decreased water compressibility and slower chemical reaction between the pore water and $\mathrm{CO}_{2}$ (Obdam et al., 2003). The Linfanjia and Shanghe oilfields in the Huimin sub- basin have average porosities of $31 \%$ and $19 \%$ respectively and measured permeabilities of $390 \mathrm{mD}$ and $11-150$ $\mathrm{mD}$.

There is more uncertainty in estimation of aquifer storage potential as a result of limited data availability due to general lack of commercial interest in deep saline aquifers. Storage capacity for the Huimin sub-basin was estimated to be $23 \mathrm{Gt}$ in the Huimin sub-basin using equation 5. Areas where the sandstone is thickest were also identified as potential targets for further study; the capacity of these areas within the sub-basin was estimated to be $0.7 \mathrm{Gt}$. The storage assessment for the Huimin subbasin strongly suggests there are areas worth further investigation. However, the storage estimates and assessment need further study with more detailed data to improve accuracy of the assessment and to identify closed structures as targets for storage.

\section{Summary}

Based on storage site potentials evaluated by the $\mathrm{COACH}$ partners, it is considered that the Dagang oilfield province is not suitable for large-scale storage, though could be considered for EOR pilots. The Shengli oilfield province was considered more promising for storage. Storage potential in the Kailuan mining area is low due to the low permeability and the risk affecting future energy resources. There may some 
potential for enhanced coalbed methane recovery though care would have to be taken not to contaminate future energy resources and to avoid risk of leakage. On initial evaluation, the Guantao Formation in the Jiyang Depression has a large potential storage capacity, though this should be considered with caution as it does not have the benefit of proven ability to store buoyant fluids and less data are available for detailed evaluation of the potential for storage.

\section{Acknowledgements}

The authors wish to thank and Beibei Zhang and John Williams for their contribution to this paper. The authors would also like to thank the reviewers for their guidance in preparing this paper.

\section{References:}

Bachu, S., Bonijoly, D., Bradshaw, J., Burruss, R., Christensen, N. P., Holloway, S. and Mathiassen. O-M. 2007 Phase II Final Report from the Task Force for Review and Identification of Standards for $\mathrm{CO}_{2}$ Storage Capacity Estimation: Estimation of $\mathrm{CO}_{2}$ storage capacity in geological media - phase 2

BACHU, S. 2008b Phase III report - Comparison between methodologies recommended for estimation of $\mathrm{CO}_{2}$ storage capacity in geological media by the CSLF task force on $\mathrm{CO}_{2}$ storage capacity estimation and the USDOE capacity and fairways subgroup of the regional carbon sequestration partnerships program. CSLFT-2008-04

Benson, S. M., Oldenburg, C., Hoversten, M. And Imbus, S. (editors) 2005. Carbon Dioxide Capture for Storage in Deep Geologic Formations - Results from the $\mathrm{CO}_{2}$ Capture Project Geologic Storage of Carbon Dioxide with Monitoring and Verification. Elsevier Press. 1331 pages.

C\&C RESERVOIRS 1998 Gudao Field, Bohai Basin, China - Far East - onshore Bohai Basin, east. China - Miocene Guantao Formation reservoir CUI, X, Bustin, R.M. AND ChiKatamarla, L., 2007. Adsorption-induced coal swelling and stress: Implications for methane production and acid gas sequestration into coal seams. J. Geophys. Res. In press.

Donaldson, E. C., Chilingarian, G. V. And Yen, T. F. (editors). 1989. Enhanced oil recovery I, fundamentals and analysis. Developments in petroleum Science 17A. Elsevier publications.

Obdam, A., van der Meer, L., May, F., Kervevan, C., Bech, N. \& Wildenborg, A. 2003. Effective CO2 storage capacity in aquifers, gas fields, oil fields and coal fields. In: GALE, J. \& KAYA, Y. (EDS.) Greenhouse Gas Control Technologies (Proceedings of the 6th International Conference on Greenhouse Gas Control Technologies, Kyoto, Japan, October 2002). 1, 339 - 344, Pergamon, Oxford (UK). 
Poulsen, N. E., VAngkilde-Pederson, T., Vincent, C., J,. Kirk, K. L., Vosgerau, H. J., ZENG, R., LI., M., ChEN, W., Ding, G. AND DAI, S,. 2009 Improving methodologies for storage capacity and site selection criteria, Deliverable 3.3 for the $\mathrm{COACH}$ project. $45 \mathrm{pp}$.

SHI, J.-Q. AND DURUCAN, S. 2005. A numerical simulation study of the Allison Unit $\mathrm{CO}_{2}$-ECBM pilot: the effect of matrix shrinkage and swelling on ECBM production and $\mathrm{CO}_{2}$ injectivity. In: Rubin, E.S., Keith, D.W., Gilboy, C.F. (Eds.), Proceedings of the Seventh International Conference on Greenhouse Gas Control Technologies, vol. 1: Peer-Reviewed Papers and Overviews. Elsevier, pp. 431-439.

Tanaka, S., Koide, H. And Sasagawa, A. 1995. Possibility of underground $\mathrm{CO}_{2}$ sequestration in Japan. Energy Conversion and Management 36(6-9) 527-530.

Vangkilde-Pedersen, T., Neele, F., van der Meer, B., Egberts, P., Wójcicki, A., Bossie-Codreanu, D., Le Nindre, Y. M. AND BARThÉLÉMY, Y. 2008. Storage capacity standards. EU GeoCapacity deliverable D24. 39 pp. 